\section{Kids, There's an App for That!}

T This morning, while watching the snow fall, a friend and I discussed making improvements in health education for the public using computer-based tools. We launched into this after a vigorous discussion about the merits and pitfalls of universal germline testing in patients with cancer and wondering how in the world you might automate genetic counseling to accommodate it.

This conversation got me thinking about what might already be available for patients with cancer, and I immediately thought about chemotherapy education. This is something our nursing staff provides in person to patients (and is available for specific cancer types through the NCCN Guidelines for Patients at NCCN.org/ patients), but wouldn't it be nice to supplement this with an electronic tool, like an app, that you can interact with? Putting my Luddite nature aside, I actually searched for this in the App Store. And although I didn't find anything that met the spirit of our discussion, I did find a wonderful app that I want to introduce you to.

I was attracted to it because it had a cheerful cartoon figure, not too dissimilar from a Despicable Me character, with bright colors and the title Kids' Guide to Cancer. It was developed as an informational tool for kids with cancer or kids living with someone who has cancer. It's an Australian product sponsored by the Newcastle Permanent Charitable Foundation (www.newcastlepermanent.com.au/ charitable-foundation), which supports activities that improve community health, especially for disadvantaged and at-risk young people.

Back to the app-which is free, by the way. I explored the whole thing. I figured that if you could teach kids about cancer, you could surely teach adults! Anyway, I found it entertaining, informative, sensitive, and extremely easy to navigate. The illustrations were dynamic and the language, while simple, did not "dumb down" the subject. In appropriate sections, the app introduced information about prevention, such as the HPV vaccine and sunscreen. So, while learning about the cancer that is affecting their grandmother, for example, kids can also learn something to help themselves.

The bottom line here is that we need more of these tools. Furthermore, we need the people who know how to make these tools entertaining to engage with us in their development. Yes, I'm taking about gamers. After all, there is a reason some folks are glued to devices for hours at a time-because it's fun! Why can't education be fun, too, even when it's about a serious subject?

This was a good exercise for me, and I found an app I can recommend to parents struggling to explain their situation to their kids. I always thought there was a void there. Additionally, I have new respect for computer-based learning, and some ideas about taking it to a new level with animation and rewards!

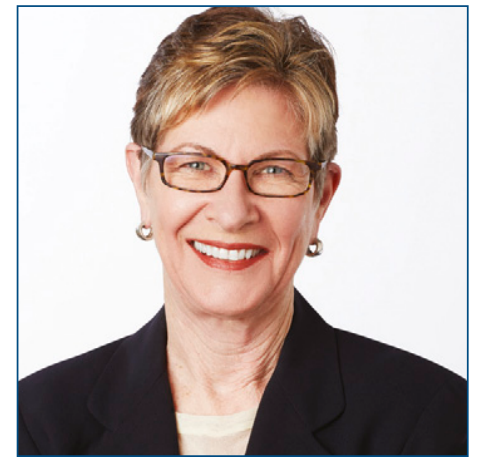

MARGARET TEMPERO, MD

Margaret Tempero, MD, is a Professor of Medicine and Director of the UCSF Pancreas Center and editor-in-chief of JNCCN. Her research career has focused on pancreatic ductal adenocarcinoma, especially in the area of investigational therapeutics. Dr. Tempero has served on the ASCO Board of Directors and as ASCO President. She currently serves on the ASCO Conquer Cancer Foundation Board. She codirected the AACR/ASCO Methods in Clinical Cancer Research and taught this course and similar courses in Europe and Australia. She was founding Chair of the $\mathrm{NCl}$ Clinical Oncology Study Section and served as a member and Chair of the $\mathrm{NCl}$ Board of Scientific Counselors Subcommittee A. She is a member of the Scientific Steering Committee and Chair of the Clinical and Translational Study Section for the Cancer Prevention \& Research Institute of Texas. She is or has been on the Scientific Advisory Boards of the Lustgarten Foundation, the Pancreatic Cancer Action Network, the V Foundation, The Alberta Canada Cancer Board, and the EORTC. She served as a member of the Oncology Drug Advisory Committee for the FDA. She has served as Deputy Director and Interim Director for the UNMC Eppley Cancer Center. She is Chief Emeritus of the Division of Medical Oncology at UCSF and served as the founding Deputy Director and Director of Research Programs at the UCSF Helen Diller Family Comprehensive Cancer Center.

doi: $10.6004 /$ jnccn.2019.0010

The ideas and viewpoints expressed in this editorial are those of the author and do not necessarily represent any policy, position, or program of NCCN. 